\title{
Pengaruh Senam Hamil Terhadap Nyeri Punggung Bawah Pada Ibu Hamil Trimester III
}

\section{The Effect Of Gymnastics on Lower Back Pain Among Pregnant Women Trimester III}

\author{
Dewi Nopiska Lilis \\ Poltekkes Kemenkes Jambi \\ e-mail: dewinopiskalilis@gmail.com
}

\begin{abstract}
Abstrak
Postur tubuh yang tidak tepat dimasa kehamilan dapat berakibat peregangan tambahan dan kele lahan pada tubuh, terutama pada tulang belakang, pelv is dan sendi penahan -berat, sehingga hal ini dapat me mbawa dampak pada peningkatan rasa nyeri dan sakit. Nyeri punggung bawah adalah suatu sindroma nyeri yang terjadi pada region punggung bagian bawah sebagai akibat dari pengaruh gravitasi tubuh yang berpindah ke depan. Upaya yang dilaku kan untuk pencegahan nyeri punggung pada ibu hamilsalah satunya adalah senamhamil. Senam hamil adalah latihan-latihan bagi ibu hamil yang bertujuan membuat elastisitas otot dan ligamen yang ada dipanggul, me mperbaiki sikap tubuh mengatur kontraksi dan relaksasi serta mengatur tehnik pernafasan. Tujuan penelitian ini untuk mengetahui pengaruh senam hamil terhadap nyeri punggung bawah pada ibu hamil trimester III di Puskesmas Putri Ayu Kota Jambi Tahun 2019. Penelitian in i merupakan penelitian pra eksperimental dengan one group pretest-posttest design. Penelitian ini dilaksanakan di Puskesmas Putri Ayu dari bulan Januari -Juli 2019. Sampel dalam penelitian ini adalah ibu hamil di Puskes mas Putri Ayu berjumlah 30 orang. Sebelu m diberikan senam ha mil responden yang mengalami nyeri berat ada $10 \%$ (3), sedang $70 \%$ (21), dan ringan20\% (6). Setelah diberikan senam hamiltidak ada yang mengalami nyeri berat, nyeri sedang berkurang tinggal menjadi 1 orang $(3,3 \%)$, nyeri ringan berkurang menjadi 19 orang $(63,3 \%)$, dan sudah tidak merasa nyeri ada 10 orang $(33,3 \%)$. Re rata tingkat nyeri yang diperoleh sebelum senam hamil sebesar 2,90 dan setelah senam hamil 1,70 sehingga terjadi penurunan sebesar 1,2 dan penurunan ini signifikan dengan nilai $p 0,0001$.
\end{abstract}

Kata kunci: senam hamil, ibu hamil, nyeri bawah punggung,

\begin{abstract}
Improper posture during pregnancy can result in additional stretching and fatigue in the body, especially in the spine, pelvis and weight-bearing joints, so this can have an impact on increasing aches and pains. Lower back pain is a pain syndrome that occurs in the lower back region as a result of the gravitational influence of the body moving forward. Efforts are made to prevent back pain in pregnant women one of which is pregnancy exercise. Pregnancy exercises are exercises for pregnant wo men that aim to make the elasticity of muscles and ligaments in the pelvis, improve posture to regulate contractions and relaxation and regulate breathing techniques. The purpose of this study is determine the effect of pregnancy exercise on low back pain in third trimester pregnant wo men. This research is a pre-experimental research with one group pretest-posttest design. This research was conducted at the PutriAyu Community Health Center from January-July 2019. The sample in this study was 30 pregnant. The Result show that by giving pregnancy exercises respondents experienced severe pain were $10 \%$ (3), moderate $70 \%$ (21), and mild $20 \%$ (6). After being given pregnancy exercises, no one experienced severe pain, moderate pain decreased to 1 pers on $(3.3 \%)$, mild pain reduced to 19 people $(63.3 \%)$, and no longer felt pain, there were 10 people $(33.3 \%)$. The mean pain level obtained before pregnancy exercises was 2.90 and after pregnancy exercises 1.70 so that there was a decrease of 1.2 and this decrease was significant with a $p$ value of 0.0001 .
\end{abstract}

Keywords: pregnancy exercise, pregnant women, lower back pain, 


\section{PENDAHULUAN}

Pada masa kehamilan, seiring dengan membesarnya uterus, pusat gravitasi berpindah kearah depan dan perpindahan ini menyebabkan ibu harus menyesuaikan posisi berdirinya. Postur semacam ini akan bergantung pada kekuatan otot, penambahan berat badan, sifat relaksasi sendi, kelelahan serta postur sebelum hamil. Perubahan ini sering kali, namun tidak selalu, memicu lengkung lumbar (lordosis) dan lengkung kompensasi spinalis toraktik (kifosis). Mekanisme ini terjadi antara bulan ke-4 dan ke-9 masa kehamilan dan terus berlangsung sampai 12 minggu masa pascanatal $^{1}$.

Postur tubuh yang tidak tepat dimasa kehamilan dapat berakibat peregangan tambahan dan kelelahan pada tubuh, terutama pada tulang belakang, pelvis dan sendi penahan-berat, sehingga hal ini dapat membawa dampak pada peningkatan rasa nyeri dan sakit. Pada suatu kajian yang dilakukan oleh Bullock et al (1991), menemukan bahwa sekitar 88,2 \% wanita mengalami nyeri punggung pada beberapa tahapan kehamilan. Ketika diajukan pertanyaan pada masa gestasi antara minggu ke-14 dan minggu ke-22, sebanyak $62 \%$ wanita melaporkan menderita nyeri punggung ${ }^{1}$.

Nyeri punggung bawah (Low Back Pain) adalah suatu sindroma nyeri yang terjadi pada region punggung bagian bawah sebagai akibat dari pengaruh gravitasi tubuh yang berpindah ke depan. Gangguan ini ditemukan pada ibu hamil ${ }^{2}$.

Faktor predisposisi nyeri punggung meliputi pertumbuhan uterus yang menyebabkan perubahan postur, penambahan berat badan, pengaruh hormon relaksin terhadap ligamen, riwayat nyeri punggung terdahulu, paritas dan aktivitas. Pertumbuhan uterus yang sejalan dengan perkembangan kehamilan mengakibatkan teregangnya ligamen penopang yang biasanya dirasakan ibu sebagai spasme menusuk yang sangat nyeri yang disebut dengan nyeri ligamen. Hal inilah yang menyebabkan nyeri punggung ${ }^{3}$.

Upaya yang dapat dilakukan adalah memberikan pendidikan kesehatan tentang pencegahan atau penanganan nyeri punggung pada ibu hamil salah satunya adalah senam hamil meliputi latihan transversus, latihan dasar pelvis dan peregangan umumnya.Latihan ini melatih tonus otot abdomen transversal bagian dalam yang merupakan penopang postural utama dari tulang belakang selama hamil ${ }^{1}$.

Pentingnya latihan fisik relaksasi senam hamil dapat bermanfaat untuk mengendurkan setiap sendi-sendi yang kaku dan sakit akibat bertambahnya beban pada ibu hamil, mengurangi keluhan yang timbul akibat perubahan bentuk tubuh, memperkuat dan mempertahankan elastisitas otot-otot dinding perut, sehingga dapat mencegah atau mengatasi keluhan nyeri di punggung bawah ${ }^{4}$.

Melakukan senam hamil secara teratur dapat menurunkan nyeri punggung bawah, salah satunya dengan gerakan berlutut memutar tulang panggul, menekuk bokong, menekuk, lutut, dada ${ }^{5}$.Jika nyeri punggung tidak segera diatasi, ini bisa mengakibatkan nyeri punggung jangka panjang, meningkatkan kecenderungan nyeri punggung pasca partum dan nyeri punggung kronis yang akan lebih sulit untuk diobati atau disembuhkan ${ }^{1}$.

Berdasarkan hasil survey awal di Puskesmas Putri Ayu melalui wawancara singkat dengan 10 orang ibu hamil didapat semua ibu hamil mengatakan mengeluh nyeri pinggang bawah. Saat ditanya mengenai aktivitas senam hamil $4 \mathrm{ibu}$ hamil menjawab pernah melakukan tetapi tidak 
teratur dan 6 diantaranya tidak pernah melakukan senam hamil.Meskipun sebelumnya pernah dilaksanakan program senam hamil namun banyak diantara ibuibu hamil yang tidak mengikuti program tersebut, adapun ibu hamil yang mengikuti program senam hamil tetap saja mengeluhkan nyeri pada pinggangnya. Hal ini disebabkan oleh ketidakteraturan ibu hamil dalam melaksanakan senam hamil.

Berdasarkan fenomena data-data di atas, maka penulis tertarik untuk melakukan sebuah penelitian yang bertujuan untuk mengetahui pengaruh senam hamil terhadap nyeri punggung bawah pada ibu hamil trimester III di Puskesmas Putri Ayu Kota Jambi Tahun 2019.

\section{METODE}

Penelitian ini merupakan penelitian pra eksperimental dengan one group pretestposttest design. Penelitian ini dilaksanakan di Puskesmas Putri Ayu. Pelaksanaan penelitian dimulai pada bulan Januari sampai dengan Juli 2019.

Populasi dalam penelitian ini adalah semua ibu hamil trimester III yang ada di Puskesmas Putri Ayu sampai bulan Juli 2019. Sampel dalam penelitian ini adalah sebagian ibu hamil di Puskesmas Putri Ayu berjumlah 30 orang.

Berdasarkan teori Sugiyono ${ }^{6}$ bahwa untuk penelitian eksperimen yang sederhana, yang menggunakan kelompok eksperimen dan kelompok kontrol maka jumlah anggota sampel masing-masing antara $10 \mathrm{~s} / \mathrm{d}$ 30. Sampel ditentukan berdasarkan kriteria inklusi yaitu ibu hamil yang dinyatakansehatolehdokter/bidan; tidak menderita penyakit/komplikasi; dan ibuhamilusiakehamilan trimester III

Instrumen yang digunakan dalam penelitian ini untuk variabel independen yaitu senam hamil menggunakan Leaflet dan
SOP teknik senam hamil sedangkan untuk variabel dependen yaitu pengukuran nyeri punggung peneliti menggunakan lembar observasi intensitas nyeri yaitu Visual Analogue Scale.

Analisa data yang digunakan dalam penelitian ini adalah analis is univariat dan analisis bivariat. Uji yang digunakan untuk mengolah data tentang perubahan skala nyeri sebelum dan setelah dilakukan terapi senam hamiladalah paired sample t-test dengan batas kemaknaan $5 \%$.

\section{HASIL DAN PEMBAHASAN}

3.1 Karakteristik Responden

Karakteristik responden penelitian di tunjukkan pada tabel berikut ini.

Tabel 1. Karakteristik Responden Senam Hamil

\begin{tabular}{|c|c|c|}
\hline Variabel & $\mathbf{n}$ & $\%$ \\
\hline \multicolumn{3}{|l|}{ Umur } \\
\hline$<20$ Tahun & 1 & 3,3 \\
\hline 20-35 Tahun & 25 & 83,3 \\
\hline >35 Tahun & 4 & 13,3 \\
\hline \multicolumn{3}{|l|}{ Pendidikan } \\
\hline SD & 3 & 10 \\
\hline SMP & 15 & 50 \\
\hline SMA & 12 & 40 \\
\hline PT & 0 & 0 \\
\hline \multicolumn{3}{|l|}{ Pekerjaan } \\
\hline TidakBekerja & 19 & 63,3 \\
\hline Bekerja & 11 & 36,7 \\
\hline \multicolumn{3}{|l|}{ Paritas } \\
\hline Primimultipara & 6 & 20 \\
\hline Multipara & 17 & 56,7 \\
\hline Grandemultipara & $\underline{7}$ & $\underline{23,3}$ \\
\hline
\end{tabular}

Berdasarkan Tabell didapatkan hasil bahwa mayoritas responden berumur antara 20-35 tahun sebanyak 25 orang (83,3\%), Sebagian responden berpendidikan SMP sebanyak 15 orang (50\%), Lebih dari separuh responden tidak bekerja sebanyak 
19 orang $(63,3 \%)$, sebagian responden memiliki paritas dengan multipara sebanyak 17 orang $(56,7 \%)$.

3.2 Gambaran tingkat nyeri punggung bawah sebelum diberikan senam hamil pada ibu hamil trimester III

Tingkat nyeri pada ibu hamil sebelum diberikan senam hamil ditunjukkan pada tabel dibawah ini.

Tabel 2. Distribusi Frekuensi Nyeri Punggung Bawah Pada Ibu Hamil Sebelum Diberikan Senam Hamil

\begin{tabular}{lcc}
\hline \multirow{2}{*}{ Variabel } & \multicolumn{2}{c}{ SebelumSenamHamil } \\
\cline { 2 - 2 } Tingkat Nyeri & $\mathrm{n}$ & $\underline{\%}$ \\
Tidak Nyeri & 0 & 0 \\
Nyeri Ringan & 6 & 20 \\
Nyeri Sedang & 21 & 70 \\
Nyeri Berat & 3 & 10 \\
Nyeri Sangat & 0 & 0 \\
Berat & & \\
Sumber: Data primer 2019 &
\end{tabular}

Nyeri punggung sangat sering terjadi dalam kehamilan sehingga digambarkan sebagai salah satu gangguan minor dalam kehamilan. Ibu hamil mencondongkan perut sehingga menambah lengkungan pada bagian bawah punggung yang menimbulkan rasa nyeri ${ }^{7}$.

Berdasarkan Tabel 2 di atas menunjukkan bahwa responden sebelum diberikan perlakuan senam hamil terdapat variasi nyeri yang dialami yaitu berat ada 3 orang (10\%) sedang ada 21 orang $(70 \%)$ dan ringan sebanyak 6 orang $(20 \%)$. artinya bahwa $100 \%$ ibu hamil mengalami nyeri walaupun tingkatannya berbeda.

Hasil ini diperkuat oleh penelitian yang dilakukan oleh Lichayati dan Kartikasari $^{8}$ tentang Hubungan senam hamil dengan nyeri punggung pada ibu hamil di Polindes Desa Lanak Kecamatan Kedung Pring Kabupaten Lamongan, hasil penelitiannya menunjukkan bahwa lebih dari sebagian $(75 \%)$ ibu hamil yang tidak pernah melakukan senam hamil mengalami nyeri punggung.

3.3 Gambaran tingkat nyeri punggung bawah sesudah diberikan senam hamil pada ibu hamil trimester III

Tabel 3. Distribusi Frekuensi Nyeri Punggung Bawah Pada Ibu Hamil Sebelum Diberikan Senam Hamil

\begin{tabular}{ccc}
\hline \multirow{2}{*}{ Variabel } & \multicolumn{2}{c}{ SetelahSenamHamil } \\
\cline { 2 - 2 } Tingkat Nyeri & $\mathrm{n}$ & $\underline{\%}$ \\
\cline { 2 - 2 } Tidak Nyeri & 10 & 33,3 \\
Nyeri Ringan & 19 & 63,3 \\
Nyeri Sedang & 1 & 3,3 \\
Nyeri Berat & 0 & 0 \\
Nyeri Sangat Berat & 0 & 0 \\
\hline
\end{tabular}

Sumber: Data primer 2019

Gambaran nyeri punggung bawah pada ibu hamil setelah melakukan senam hamil pada Tabel 3 menunjukkan bahwa setelah diberikan perlakuan senam hamil tidak terdapat ibu hamil yang mengalami nyeri berat, nyeri ringan berkurang menjadi $3,3 \%$ dan tidak mengalami nyeri sebesar $33,3 \%$. Dengan melakukan senam hamil akan banyak memberikan manfaat antara lain dapat melatih pernapasan dan relaksasi, menguatkan otot-otot panggul dan perut, serta melatih cara mengedan yang benar ${ }^{9}$.

Hasil ini diperkuat oleh penelitian Lichayati dan Kartikasari ${ }^{8}$ yang menunjukkan bahwa seluruh $(100 \%)$ ibu hamil yang sering melakukan senam hamil tidak mengalami nyeri punggung. Dengan demikian ibu hamil yang melakukan senam hamil secara teratur maka semakin kecil mengalami keluhan nyeri punggung.

3.4 Pengaruh Senam Ibu Hamil Terhadap nyeri punggung bawah ibu hamil trimester III

Hasil analisis tentang penurunan nyeri sebelum diberikan senam hamil dan 
sesudah diberikan senam hamil terhadap penurunan nyeri punggung bawah ibu hamil trimester III di Puskesmas PutriAyu Tahun 2019 dengan menggunakan uji T

Tabel 4. Pengaruh Senam Ibu Hamil Terhadap nyeri punggung bawah ibu hamil trimester III

\begin{tabular}{|c|c|c|c|c|}
\hline $\begin{array}{c}\text { Tingkat } \\
\text { Nyeri }\end{array}$ & Mean & SD & $\mathrm{T}_{\text {hitung }}$ & $\begin{array}{c}\mathrm{P}- \\
\text { Value }\end{array}$ \\
\hline Pretest & 2.90 & 0.548 & 16.155 & 0.000 \\
\hline Posttest & 1.70 & $\underline{0.535}$ & $10.15 J$ & 0.000 \\
\hline
\end{tabular}

Sumber: Data primer 2019

Pada Tabel 4 diketahui bahwa nilai rata-rata tingkat nyeri sebelum dilakukan senam hamil yaitu 2.90 dan rata-rata tingkat nyeri sesudah dilakukan senam hamil yaitu 1.70. Hasil analisis uji statistik didapatkan adanya penurunan yang signifikan antara mean intensitas nyeri sebelum dan sesudah diberikan senam hamil dimana $p$-value 0.000 lebih kecil dari nilai alpha $(p<\alpha$ (0.05),berarti dapat disimpulkan bahwa senam hamil efektif dalam menurunkan intensitas nyeri punggung.

Manfaat senam hamil antara lain, menyesuaikan tubuh agar lebih baik dalam menyangga beban kehamilan, memperkuat otot untuk menopang tekanan tambahan, membangun daya tahan tubuh, memperbaiki sirkulasi dan respirasi, menyesuaikan dengan adanya pertambahan berat badan dan perubahan keseimbangan, meredakan ketegangan dan membantu relaks, membentuk kebiasaan bernafas yang baik, memperoleh kepercayaan dan sikap mental yang baik ${ }^{10}$.

Hal ini diperkuat oleh penelitian yang sudah dilakukan sebelumnya di berbagai tempat di Indonesia yang menunjukkan adanya penurunan tingkat nyeri punggung bawah secara signifikan $(p<0,05)$ setelah seorang ibu hamil trimester III secara rutin melakukan aktivitas senam hamil $^{8,11,12,13,14,15}$.
Senam hamil yang dilakukan secara teratur dapat mengurangi nyeri punggung karena gerakan yang terdapat didalam senam hamil mampu memperkuat otot abdomen sehingga mencegah tegangan yang berlebihan pada ligamen pelvis sehingga intensitas nyeri pungung menjadi berkurang. Selain itu melakukan senam hamil mampu mengeluarkan b-endorphin didalam tubuh, dimana fungsi $b$-endorphin yaitu sebagai penenang dan mampu mengurangi nyeri pinggang pada ibu hamil $^{11}$.

\section{KESIMPULAN}

Dari hasil penelitian yang sudah dilakukan dapat disimpulkan bahwa nyeri punggung bawah pada ibu hamil trimester III sebelum diberikan senam hamil didapatkan lebih dari sebagian responden mengalami nyeri sedang. Terdapat perubahan tingkat Nyeri punggung bawah pada ibu hamil trimester III sesudah diberikan senam hamil yaitu didapatkan sebagian responden mengalami nyeri ringan. Senam hamil efektif dalam menurunkan intensitas nyeri punggung pada ibu hamil trimester III di Pukesmas Putri Ayu.

\section{UCAPAN TERIMA KASIH}

Peneliti mengucapkan terima kasih kepada responden yang telah berpartisipasi langsung pada penelitian ini dan pihakpihak yang telah berkontribusi pada penelitian ini.

\section{DAFTAR PUSTAKA}

1. Brayshaw, E. Senam hamil dan Nifas Pedoman Praktik Bidan. Jakarta:EGC; 2008. 
2. McClammy, J. Pregnancy and Low Back Pain, Triangle Spine and Back Care Center. 2007.

3. Fraser, D.M. Buku Ajar Bidan Myles.Jakarta: EGC; 2009.

4. Saminem, H. 2009. KehamilanNormal : Seri AsuhanKebidanan. Jakarta :EGC; 2009

5. Tamsuri. A. Konsep dan penatalaksanaan nyeri. Jakarta : EGC; 2007

6. Sugiyono. Metode Penelitian Kuantitatif, Kualitatif dan R\&D. Bandung: Afabeta; 2011

7. Varney. Buku Ajar Asuhan Kebidanan, Ed. 4, Vol. 1. Jakarta: EGC; 2007

8. Lichayati, dan Kartikasari. Hubungan Senam Hamil Dengan Nyeri Punggung Pada Ibu Hamil di Polindes Desa Tlanak Kecamatan Kedung Pring Kabupaten Lamongan. Jurnal Surya,2013; 1(XIV)

9. Aliyah. Pengaruh Pemberian Senam Hamil Terhadap Tingkat Kecemasan Dan Kualitas Tidur Ibu Hamil Di Puskesmas Samata Kabupaten Gowa. Skripsi.Program Studi Fisioterapi Fakultas Kedokteran Universitas Hasanuddin Makassar; 2016

10. Maryunani. Senam Hamil, Senam Nifas dan Terapi Musik. Jakarta: Trans Info Media; 2011

11. Yosefa, dkk. Efektifitas Senam Hamil Terhadap Penurunan Nyeri Punggung Pada Ibu Hamil. Program Studi Ilmu Keperawatan. Universitas Riau. 2014.

12. Delima, dkk, 2015. Pengaruh Senam Hamil Terhadap Penurunan Tingkat Nyeri Punggung Bawah Pada Ibu Hamil Trimester II dan III di Puskesmas Parit Rantang Payakumbuh Tahun 2015. Jurnal Kesehatan Perintis. 2015; 2(2)

13. Prosiding.Pengaruh Senam Hamil Terhadap Perubahan DerajatNyeri Pada Ibu Hamil Yang MenderitaNyeri Pinggang Bawah (NPB). Skripsi.
Program Studi FisioterapiFakultas KedokteranUniversitas

HasanuddinMakassar; 2016.

14. Anggeriani. Pengaruh Senam Hamil Terhadap Penurunan Rasa Nyeri Punggung Pada Ibu Hamil Trimester III. Jurnal. Cendekia Medika. 2015; 3(1): 2620-5424

15. Firdayani. Pengaruh Senam Hamil Terhadap Penurunan Nyeri Punggung Bawah Pada Ibu Hamil Trimester II dan III di BPM Aminatur Rofiah, SST di Desa Sepanyul Kecamatan Gudo Kabupaten Jombang. Skripsi. Program Studi DIV BidanPendidik Sekolah Tinggi Ilmu Kesehatan Insan Cendekia Medika Jombang; 2018. 